\title{
O009. Early pain relief from orthostatic headache and hearing changes, assessed with the visual analogue scale, in spontaneous intracranial hypotension after epidural blood patch in Trendelenburg position: 28 case reports
}

\author{
Enrico Ferrante $^{1 *}$, Valentina Sangallii ${ }^{1}$, Elena Olgiati ${ }^{2}$, Fabio Rubino $^{3}$, Elio Agostoni ${ }^{1}$
}

From Abstracts from the 1st Joint ANIRCEF-SISC Congress

Rome, Italy. 29-31 October 2015

\section{Background}

Spontaneous intracranial hypotension (SIH) is characterized by orthostatic headache $(\mathrm{OH})$, diffuse pachymeningeal enhancement on brain MRI and low CSF pressure. Hearing change $(\mathrm{HC})$ is a frequent finding. Epidural blood patch (EBP) is now the most recommended available treatment. Our study aimed at investigating the EBP efficacy on $\mathrm{OH}$ and $\mathrm{HC}$ by asking patients to rate their $\mathrm{OH}$ and $\mathrm{HC}$ at different time intervals with a visual analogue scale (VAS).

\section{Materials and methods}

Twenty-eight consecutive patients with SIH were treated with EBP in Trendelenburg position. Two Psychologists asked them to rate, on a VAS, the intensity of their $\mathrm{OH}$ and $\mathrm{HC}$ before, 24 hours after, and two months after treatment.

\section{Results}

A significant improvement in $\mathrm{OH}$ and $\mathrm{HC}$ was found ( $p$ < .001) 24/48 hours after EBP. When followed-up, all patients showed complete relief from $\mathrm{OH}$. Four patients out of 16 reported very mild $\mathrm{HC}$.

\section{Discussion and conclusions}

To the best of our knowledge, this is the first time a specific pain assessment with VAS was conducted before and after EBP, showing a fast improvement of $\mathrm{OH}$ and

\footnotetext{
* Correspondence: enricoferrante@libero.it

${ }^{1}$ Neurosciences Department, Niguarda Cà Granda Hospital, Milan, Italy

Full list of author information is available at the end of the article
}

$\mathrm{HC}$ in a large group of SIH patients. Importantly, patients have been followed up for two months and 13-25 months after discharge, which confirmed the effect to be complete and long-lasting. In a future work, it may be worth monitoring patients' changes over time with multiple follow-ups, also involving larger patients sample in a multicentric study.

Written informed consent to publication was obtained from the patient(s).

\section{Authors' details}

'Neurosciences Department, Niguarda Cà Granda Hospital, Milan, Italy. ${ }^{2}$ Imperial College London, Department of Medicine, Division of Brain Sciences, London, UK and University of Milan-Bicocca, Department of Psychology, Milan, Italy. ${ }^{3}$ Anaesthesiology Department, Niguarda Cà Granda Hospital, Milan, Italy.

\section{Published: 28 September 2015}

References

1. Ferrante E, Arpino I, Citterio A, et al: Epidural blood patch in Trendelenburg position pre-medicated with acetazolamide to treat spontaneous intracranial hypotension. Eur J Neurol 2010, 17:715-719.

2. Mokri B: Spontaneous Low Pressure, Low CSF Volume Headaches: Spontaneous CSF Leaks. Headache 2013, 53:1034-1053.

3. Ferrante $E$, Arpino I, Citterio $A$, et al: Coma resulting from spontaneous intracranial hypotension treated with the epidural blood patch in Trendelemburg position pre-medicated with acetazolamide. Clin Neurol Neurosurg 2009, 111:699-702.

\section{doi:10.1186/1129-2377-16-S1-A124}

Cite this article as: Ferrante et al: O009. Early pain relief from orthostatic headache and hearing changes, assessed with the visual analogue scale, in spontaneous intracranial hypotension after epidural blood patch in Trendelenburg position: 28 case reports. The Journal of Headache and Pain 2015 16(Suppl 1):A124. 